\title{
Evaluation of long-term bond strength and selected properties of self-adhesive resin cements
}

\section{Carianne Mendes de ALMEIDA(a) Carine Tais Welter MEEREIS(a) Fernanda Barbosa LEAL ${ }^{(a)}$ Aline Oliveira OGLIARI(a) Evandro PIVA ${ }^{(b)}$ Fabrício A OGLIARI(c)}

(a) Universidade Federal de Pelotas - UFPel, Undergraduate Program in Dentistry, Pelotas, SC, Brazil.

(b) Universidade Federal de Pelotas - UFPel, School of Dentistry, Department of Operative Dentistry, Pelotas, SC, Brasil.

(c) Universidade Federal de Pelotas - UFPel, Materials Engineering School, Department of Organic Chemistry, Pelotas, SC, Brasil.

Declaration of Interest: The authors certify that they have no commercial or associative interest that represents a conflict of interest in connection with the manuscript.

\section{Corresponding Author:}

Evandro Piva

E-mail: evpiva@gmail.com

hitps://doi.org/10.1590/1807-3107bor-2018.vol32.0015

Submitted: June 27, 2017

Accepted for publication: November 11, 2017 Last revision: January 24, 2018
Abstract: This study evaluated the shear bond strength (SBS) of self-adhesive resin cements (SARCs) to dentin and their physical-chemical properties. Five commercial SARCs were evaluated [SmartCem ${ }^{\circledR 2}$ DENTSPLY (SC2); BisCem ${ }^{\circledR}$ - Bisco (BC); SeT PP® - SDI (SeT); Relyx U100® - 3M ESPE (U100) and YCEM® SA - Yller (YCEM)]. The SARCs were evaluated for SBS to dentin $(\mathrm{n}=10)$ after $24 \mathrm{~h}, 6$ months, and 12 months. The dentin demineralization caused by acidic monomers was observed by SEM, and $\mathrm{pH}$-neutralization of eluate was observed for $24 \mathrm{~h}$. Degree of conversion (DC), rate of polymerization (Rp), flexural strength (FS), and elastic modulus (E) were evaluated. Immediate SBS of SC2, SET, U100, and YCEM were statistically higher than that of BC ( $p<0.001)$. After 12 months, all SARCs showed reduced SBS values and U100 showed values similar to those of SET and YCEM, and higher than those of BC and SC2 ( $p=0.001)$. Demineralization pattern of SARCs was similar. At $24 \mathrm{~h}$, all SARCs showed no differences in the $\mathrm{pH}$-value, except BC and U100 ( $p<0.001)$. YCEM showed the highest Rp. U100, YCEM, and SC2 showed statistically higher FS $(p<0.001)$ and $E(p<0.001)$ when compared with SET and BC. U100 and YCEM showed the best long-term bonding irrespective of the storage period. A significant reduction in SBS was found for all groups after 12 months. SBS was not shown to be correlated with physical-chemical properties, and appeared to be material-dependent. The polymerization profile suggested that an increased time of light activation, longer than that recommended by manufacturers, would be necessary to optimize DC of SARCs.

Keywords: Resin Cements;

\section{Introduction}

The clinical success of an indirect restorative procedure partly depends on the luting technique used to create a link between the restoration and the tooth. ${ }^{1}$ Self-adhesive resin cements (SARCs) have attained great popularity among clinicians ${ }^{2}$ because they simplify adhesive luting procedures by: reducing the number of steps of adhesive systems; reducing technique sensitivity, and making the cementation process simpler and faster. ${ }^{3,4,5}$ Furthermore, the use of SARCs reduces the occurrence of postoperative sensitivity, improves the retention of glass-fiber posts, ${ }^{6}$ and produces satisfactory bonding to dentin and indirect restorative materials. ${ }^{3}$ However, 
the mechanical performance of SARCs has been shown to be material-dependent and probably correlated to their chemical composition. ${ }^{7,8,9}$

The self-adhesive properties of these SARCs are attributed to the presence of acidic methacrylate monomers capable of demineralizing and infiltrating into the dental substrate ${ }^{10,11}$ resulting in micromechanical interlocking. The first SARC introduced was RelyX Unicem ${ }^{\circledR}$ (3M ESPE, Germany) and the bond strength of RelyX Unicem ${ }^{\circledR}$, has been evaluated in several studies, , $9,10,12,13,14,15,16,17,18$ with results comparable with those of multi-step luting agents available at present. ${ }^{10,12,18}$ However, the long-term storage of these SARCs to show long-term dentin bond effectiveness ${ }^{12,14,15,17}$ and mechanical stability ${ }^{19}$ has rarely been evaluated. ${ }^{12,14,15,17}$ Mechanical stability is related to high $\mathrm{pH}$-neutralization over time, which in turn renders the polymer more hydrophobic and less prone to hydrolytic degradation. ${ }^{19,20}$ Nevertheless, to the best of our knowledge, the relationship between bonding longevity and $\mathrm{pH}$-over-time has not yet been evaluated. The degree of conversion and the mechanical properties of SARC have also been assessed;,19,21,22 but no studies have evaluated the relationship between bonding longevity and their properties. Despite the satisfactory dentin bond strength behavior reported for RelyX Unicem ${ }^{\circledR}$, bond strength can vary among SARCs due to differences in composition, such as acid monomer concentration, filler particle content and photoinitiator system used. Good long-term bonding capacity is desired for clinical long-term success. ${ }^{1,11}$. Although the characteristics of Relyx Unicem ${ }^{\circledR}$ are well known, detailed information about the chemical reaction and $\mathrm{pH}$-buffering effect of most of the other SARCs now available is still lacking. ${ }^{11}$

Thus, the aim of this study was to evaluate the long-term bond strength to dentin, $\mathrm{pH}$-neutralization, kinetics of polymerization, and mechanical properties produced by five commercial SARCs. The hypothesis tested was that there would be difference between the bond strengths to dentin and other material properties produced by self-adhesive luting agents.

\section{Methodology}

\section{Materials used}

Table 1 shows the five commercially available selfadhesive resin cements (SARCs) tested in this study and data about their composition. All materials were processed according to the respective manufacturer's instructions, and the equal volume of pastes $\mathrm{A}$ and B were mixed for $30 \mathrm{~s}$ before testing for all analyses.

The light-cure mode was used for all specimen preparation and the light activation procedures were carried out using a light-emitting diode unit (Radii; SDI, Bayswater, Australia) with 1,000 mW/ $\mathrm{cm}^{2}$ irradiance.

Table 1. Materials tested in this study (manufacturer information).

\begin{tabular}{|c|c|c|c|}
\hline Code & Materials & Manufacturer & Composition \\
\hline SC2 & SmartCem2 & $\begin{array}{l}\text { Dentisply } \\
\text { (Konstanz, Germany) }\end{array}$ & $\begin{array}{l}\text { UDMA Resin, EBPADMA Urethane Resin, di-and tri-functional diluentes, } \\
\text { PENTA, Proprietary photoinitiating system, proprietary self-cure initiating } \\
\text { system, } 69 \% \text { filler by wt. }\end{array}$ \\
\hline $\mathrm{BC}$ & Biscem & $\begin{array}{c}\text { Bisco } \\
\text { (Schaumburg, USA) }\end{array}$ & $\begin{array}{l}\text { Bis (Hydroxyethyl methacrylate) phosphate, tetraethylene glycol } \\
\text { dimethacrylate, dental glass }\end{array}$ \\
\hline SET & SeT PP & $\begin{array}{l}\text { SDI } \\
\text { (Bayswater, Australia) }\end{array}$ & $\begin{array}{l}\text { Fluoro-aluminosilicate glass, urethane dimethacrylate, camphorquinone, } \\
\text { acidic monomer }\end{array}$ \\
\hline U100 & Relyx U100 & $\begin{array}{l}\text { 3M-ESPE } \\
\text { (St. Paul, USA) }\end{array}$ & $\begin{array}{l}\text { Glass powder, methacrylated phosphoric acid esters, Triethylene glycol } \\
\text { dimethacrylate, Silane treated silica, sodium persulfate cupric acetate }\end{array}$ \\
\hline \multirow[t]{2}{*}{ YCEM } & \multirow[t]{2}{*}{ YCEM AS } & \multirow[t]{2}{*}{$\begin{array}{l}\text { Yller Biomaterials } \\
\text { (Pelotas, Brazil) }\end{array}$} & $\begin{array}{l}\text { A: Dimethacrylate, acidic monomer, glass particle, silica } \\
\text { nanoparticle }\end{array}$ \\
\hline & & & B: Dimethacrylate, initiators, glass particle, silica nanoparticle \\
\hline
\end{tabular}




\section{Bond strength to dentin}

Fifty bovine incisors $(n=10)$ were embedded in acrylic resin, and their buccal surfaces were wetground to expose middle depth dentin. The dentin surfaces were wet-polished with 600 -grit $\mathrm{SiC}$ abrasive papers for $60 \mathrm{~s}$. The bovine incisors were ultrasonically cleaned in distilled water for $10 \mathrm{~min}$. Dentin moisture was controlled with the use of absorbent paper until no water was observed on surface. Polyvinylsiloxane molds (thickness $0.5 \mathrm{~mm}$ ) with a cylindrical orifice (diameter $1.5 \mathrm{~mm}$ ) were placed on the dentin surfaces. The orifices were filled with SARCs and the molds were covered with polyester strips and glass slides, and photoactivated for $20 \mathrm{~s}$. The specimens were stored in distilled water at $37^{\circ} \mathrm{C}$ for 24 hours, 6 months or 12 months. The shear bond strength test was performed using a mechanical testing machine (EMIC DL 500, Brazil) at a crosshead speed of $0.5 \mathrm{~mm} / \mathrm{min}$ until failure. A steel wire (diameter $0.2 \mathrm{~mm}$ ) was looped around the cylinder and aligned with the bonding interface. Shear bond strength (SBS) values were obtained in MPa. Failure modes were classified at $100 \mathrm{X}$ magnification and pre-testing failures were assigned a value of $0 \mathrm{MPa}$. Representative failed specimens were analyzed by scanning electron microscopy (SEM - JEOL JSM-6610/LB, USA)

\section{Demineralization pattern on dentin}

The dentin surface of bovine incisors $(n=1)$ was prepared as previously described for theSBS test. Dentin moisture was controlled with absorbent paper until no surface water was observed. The dentin surfaces were filled with theSARCs, and after 2 min were thoroughly washed and ultrasonically cleaned in acetone and distilled water for $30 \mathrm{~min}$, and dry-stored at $37^{\circ} \mathrm{C}$ for $48 \mathrm{~h}$ for the purpose of obtaining the demineralization pattern on unground dentin, caused by the acidic monomers of SARCS. The control groups consisted of dentin surfaces only polished and etched with $37 \%$ phosphoric acid for $15 \mathrm{~s}$. The demineralization pattern promoted on unground dentin was observed by SEM.

\section{Potential hydrogen $(\mathrm{pH})$ of the eluate}

The SARCs were poured into a disc-shaped polyvinylsiloxane mold (thickness $2 \mathrm{~mm}$, diameter 20 $\mathrm{mm}$ ) and light photoactivated between glass slides for
20 s on each side. The discs $(n=3)$ were individually immersed in $10 \mathrm{~mL}$ of distilled water $(\mathrm{pH}=6.0)$ and $\mathrm{pH}$ readings of the eluate were taken with a digital pHmeter (An2000; Analition, Ribeirão Preto, Brazil) at time intervals of $1,5,15,30,60,120,240,360$, and 1,400 minutes after immersion.

\section{Kinetics of polymerization (KP)}

The polymerization reaction of the SARCs was evaluated using real-time Fourier transform infrared (RT-FTIR) spectroscopy with an attenuated total reflectance device that was composed of a horizontal diamond crystal. To evaluate the degree of conversion (DC) and rate of polymerization (Rp), the SARCs were dispensed on the diamond crystal $(n=3, \sim 3 \mu \mathrm{L})$. For the materials, readouts were taken by IResolution software (SHIMADZU, USA) using a monitoring scan mode, at a rate of 1 scan per second, at Happ-Genzel apodization, and a $4 \mathrm{~cm}^{-1}$ resolution. The sample scanning was performed simultaneously with the photoactivation for $60 \mathrm{~s}$. Analysis was performed at a controlled room temperature of $23^{\circ} \mathrm{C}\left( \pm 2{ }^{\circ} \mathrm{C}\right)$ and $60 \%( \pm 5 \%)$ relative humidity. The DC (\%) and $\operatorname{Rp}\left(\mathrm{s}^{-1}\right)$ were calculated as previously described, ${ }^{23,24}$ considering the intensity of carbon-carbon double-bond stretching vibration (peak height) at 1,635 $\mathrm{cm}^{-1}$, and as an internal standard, symmetric ring stretching at $1,710 \mathrm{~cm}^{-1}$ was used from the polymerized and unpolymerized samples. The Rp was recorded as the data-curve fitting performed by Hill three-parameter non-linear regression.

\section{Flexural strength (FS) and elastic modulus (E)}

Bar-shape specimens $(n=10)$ measuring $10 \times$ $2 \times 2 \mathrm{~mm}$ were made in a metal mold, and light polymerized between glass slides in two windows for $20 \mathrm{~s}$ on each side. After $24 \mathrm{~h}$ storage in distilled water at $37^{\circ} \mathrm{C}$, in the dark, the bar-shaped dimensions were measured with a digital caliper; the flexural strength and elastic modulus ${ }^{24}$ were obtained in a three-point bending test on a mechanical testing machine (EMIC DL500) using a span of $8 \mathrm{~mm}$ and a crosshead speed of $0.5 \mathrm{~mm} / \mathrm{min}$.

\section{Statistical analysis}

The property data of each SARC were individually submitted to one-way Analysis of Variance (ANOVA). 
When data failed the normality or equal of variance tests, data were analyzed using ANOVA on Ranks. Pairwise multiple comparison procedures were carried out using the Tukey test. A significance level of $\alpha=0.05$ was set for all analyses.

\section{Results}

The dentin bond strength results are shown in Table 2. Statistical analysis showed that the factors "SARCs" and the "storage period" were both significant $(p<0.001)$. Irrespective of the material, a decrease in bond strength was observed after 6 and 12 months when compared with $24 \mathrm{~h}$. Whereas, with regard to time, irrespective of the storage period evaluated, materials U100 and YCEM presented similar SBS values, and higher than those of the other SARCs, except for SET that showed values similar to those of YCEM. When the immediate $(24 \mathrm{~h})$ bond strength of SARCs was compared, the materials SC2, SET, U100, and YCEM showed similar SBS values; SC2 and SET were similar to those of BC ( $p<0.001)$. However, BC showed median values equal to $0 \mathrm{MPa}$ for all storage periods, because of the high number of pre-test failures:

Table 2. Shear bond strength (SBS) median values in MPa and the number of pre-testing failures/total number of tested specimens ( $\mathrm{ptf} / \mathrm{n})$.

\begin{tabular}{|c|c|c|c|c|}
\hline \multirow{2}{*}{ SARCs } & \multicolumn{3}{|c|}{ Time of evaluation (SBS - ptf/n) } & \multirow{2}{*}{ Pooled average } \\
\hline & $24 \mathrm{~h}$ & $6 m$ & $12 m$ & \\
\hline \multirow{2}{*}{ SC2 } & ${ }^{A B} 5.0^{\circ}$ & ${ }^{B} 0.0^{b}$ & ${ }^{c} 0.0^{b}$ & \multirow{2}{*}{ CD 0.0} \\
\hline & $04 / 20$ & $10 / 10$ & $10 / 10$ & \\
\hline \multirow{2}{*}{$B C$} & ${ }^{\mathrm{B}} 0.0^{\circ}$ & ${ }^{\mathrm{B}} 0.0^{\circ}$ & ${ }^{B C} 0.0^{\circ}$ & \multirow{2}{*}{$\mathrm{D} 0.0$} \\
\hline & $16 / 20$ & $09 / 10$ & $06 / 10$ & \\
\hline \multirow{2}{*}{ SET } & ${ }^{A B} 4.8^{\circ}$ & $\mathrm{A} 4.1^{\mathrm{ab}}$ & ${ }^{A B C} 0.8^{b}$ & \multirow{2}{*}{ BC 3.8} \\
\hline & $04 / 20$ & $01 / 10$ & $04 / 10$ & \\
\hline \multirow{2}{*}{ U100 } & A $8.4^{\circ}$ & $\mathrm{A} 10.1^{a}$ & A $5.1^{\mathrm{b}}$ & \multirow{2}{*}{ A 7.9} \\
\hline & $0 / 20$ & $0 / 10$ & $0 / 10$ & \\
\hline \multirow{2}{*}{ YCEM } & $\mathrm{A} 8.3^{\circ}$ & ${ }^{A} 6.0$ ab & ${ }^{A B} 3.6^{b}$ & \multirow{2}{*}{ AB 5.7} \\
\hline & $0 / 20$ & $0 / 10$ & $01 / 10$ & \\
\hline $\begin{array}{l}\text { Pooled } \\
\text { average }\end{array}$ & $5.6^{\circ}$ & $3.1^{\mathrm{b}}$ & $1.1 \mathrm{~b}$ & \\
\hline
\end{tabular}

Different superscript capital letters in columns show statistical differences for SARCs $(p<0.05)$; different superscript lowercase letters in rows show statistical differences for storage period $(p<0.05)$.
$78 \%$ of specimens failed before the test. After 6 months of water storage, only material SC2 showed a decrease in the long-term bond strength values ( $p<0.001)$, and no bond to dentin ( $0 \mathrm{MPa})$. After 12 months of water storage, all SARCs showed reduced bonding effectiveness when compared with $24 \mathrm{~h}$, except BC; however, U100 bond strength values were similar to those of SET and YCEM, and significantly higher than those of BC and SC2 ( $<<0.001)$. Predominance of interfacial (adhesive) failures was detected for U100, YCEM, and SET; and pre-testing failures for $\mathrm{BC}$ and SC2 in all storage periods (Figure 1). At 6 and 12 months, increasing pre-testing failures were observed for materials BC, SC2, and SET (Figure 1). Although SET had similar bond strength values to those of U100 and YCEM, it showed $40 \%$ of pre-testing failures after 12 months. The SEM micrographs of the representative failed specimen in the SBS test at 45x and 500x magnifications are illustrated in Figure $2 \mathrm{~A}$ and B, respectively. Insert Figures 1 and 2

The SEM micrographs of the demineralization pattern on dentin are shown in Figure 3 (A-G). The positive control (37\% phosphoric acid) showed typical etched dentin with open dentinal tubules (Figure $3 \mathrm{~A}$ )

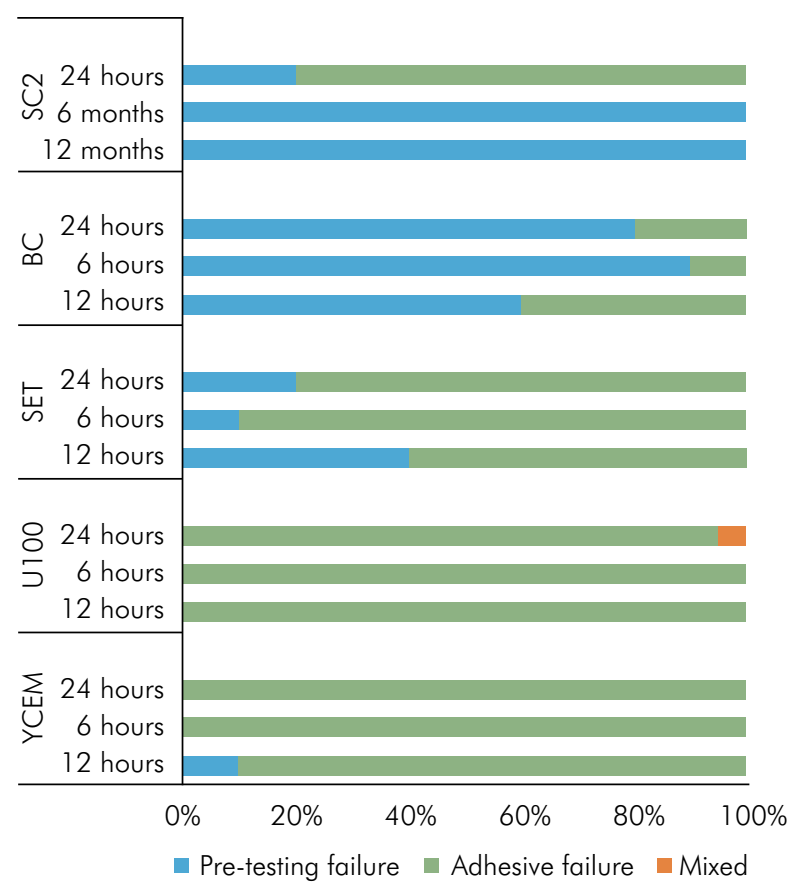

Figure 1. Failure modes 

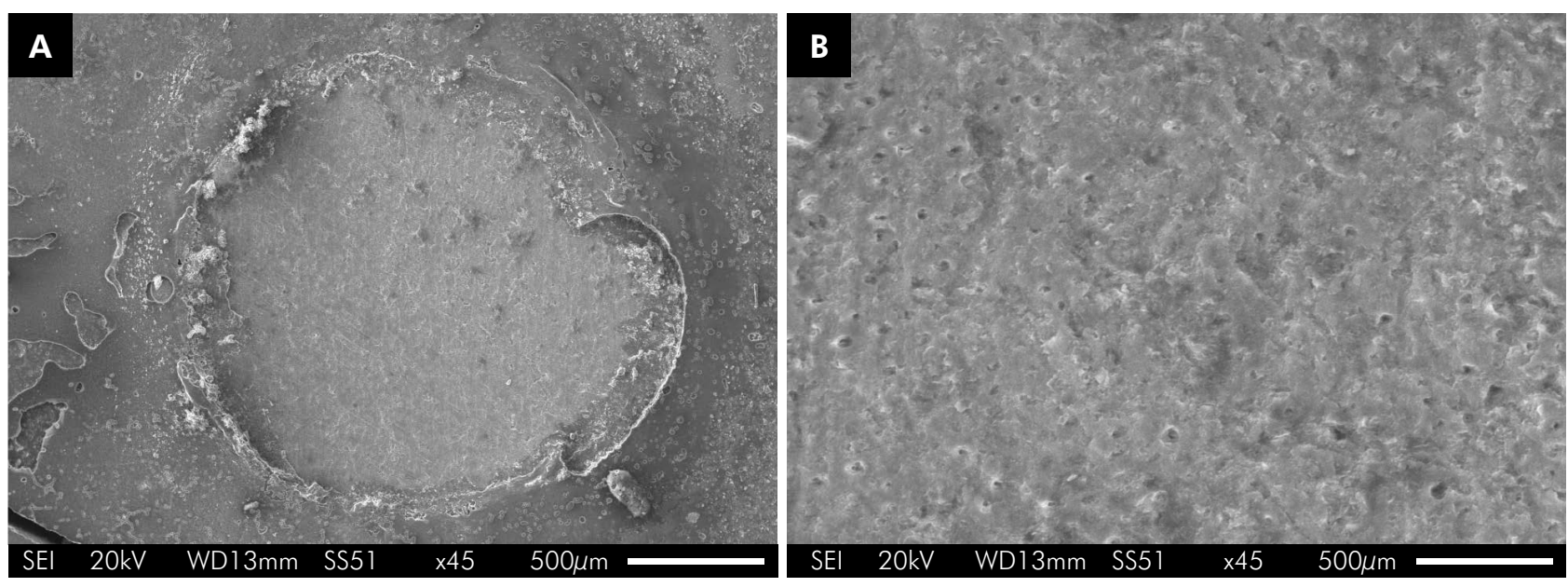

Figure 2. SEM micrographs showing the adhesive failure at lower $(45 \times-A)$ and higher $(500 \times-B)$ magnifications

and the negative control (only wet polishing) presented grooves in dentin resulting from the polishing procedure and an unmodified smear layer (Figure 3 B). The SARCs showed a similar demineralization pattern (Figure 3 C-G); the smear layer was modified by acidic monomers of the SARCs and the dentinal tubules were filled with smear plugs.

Results for the $\mathrm{pH}$ analysis are shown in Figure 4. All SARCs showed a typical profile of decreased $\mathrm{pH}$-values in the first minutes after immersion, followed by incremental increase in $\mathrm{pH}$ during 24 $\mathrm{h}$ storage, except for material YCEM that remained constant in the first hours after immersion, and showed subsequent decrease in $\mathrm{pH}$. Significant differences in the $\mathrm{pH}$-value at $24 \mathrm{~h}$ were observed among all SARCs ( $\mathrm{p}<0.001)$; U100 presented a higher $\mathrm{pH}$-value than those of the other SARCs; and SC2, SET, and YCEM values were similar each other and statistically lower than that of BC group.

Results for the kinetics of polymerization are shown in Figure 5 and Figure 6, and degree of conversion values after light polymerization of $20 \mathrm{~s}$ are shown in Table 3. Material YCEM showed degree of conversion similar to that of SC2 $(p=0.35)$ and higher than that of materials U100 and SET ( $p \leq 0.001$ ). Material BC showed values similar to those of all the other SARCs $(p \geq 0.05)$ at $20 \mathrm{~s}$ of photoactivation time (Table 3); however, after 60 s of photoactivation time SC2 showed the highest conversion values (Figure 5). Material YCEM showed the highest the rate of polymerization, while polymerization was slower in the other SARCs (Figure 6).

Materials U100, YCEM, and SC2 showed significantly higher flexural strength $(p<0.001)$ and elastic modulus $(p<0.001)$ in comparison with materials SET and BC (Table 3).

\section{Discussion}

In this study, according to the findings, the factors "SARCs" and "storage period" were both significant, thus research hypothesis was accepted. The effectiveness and the long term bond strength of SARC to dentin may be influenced by several factors such as substrate, operator technique, and composition of luting agents. In complex formulations, such as those of most adhesive resin cements, there may be a synergy between the different material components, such as the functional monomer acid, initiation system, the inorganic filler used. ${ }^{25,26}$ This mixture can affect the mechanical properties of the material and should be considered. As self-adhesive resin cements are less technique sensitive, because they do not require preparation of the substrate, their performance seems to be more material-dependent than technique-dependent.

The relatively low shear bond strength values of all SARCs could be related to superficial surface interaction with the tooth structure, without dissolving the smear layer. ${ }^{27}$ Moreover, these materials need to 

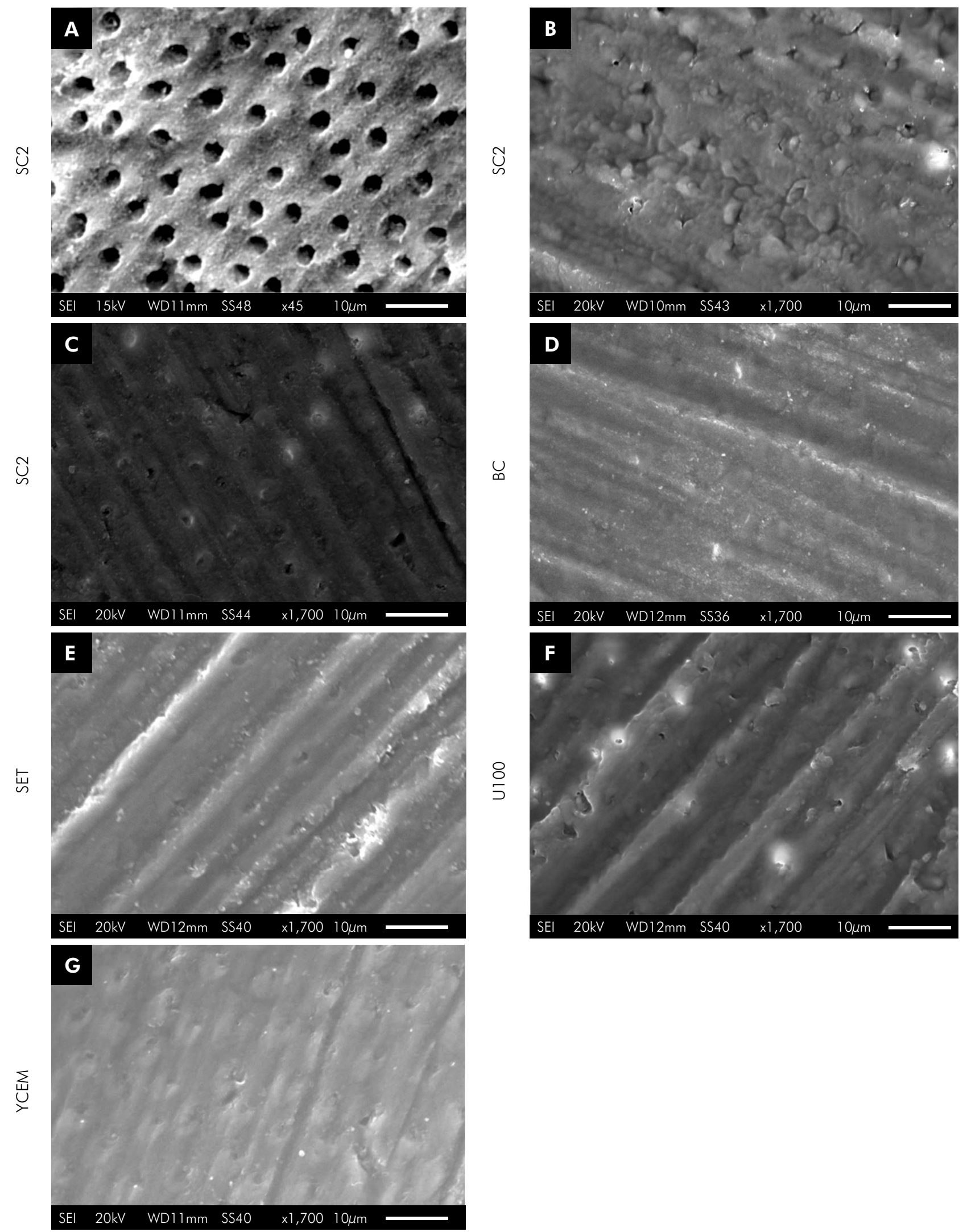

Figure 3. SEM micrographs comparing the demineralization pattern on dentin and the morphology created by acid monomers from SARCs $(C-G)$, using phosphoric acid $37 \%$ as positive control $(A)$ and wet polished specimens as negative control (B) 
Table 3. Means (standard deviations) for the physic-chemicals properties tested.

\begin{tabular}{lcccc}
\hline SARCs & $\mathrm{pH}^{*}$ & $\mathrm{DC}(\%)^{* *}$ & $\mathrm{FS}(\mathrm{MPa})$ & $\mathrm{E}(\mathrm{GPa})$ \\
\hline $\mathrm{SC} 2$ & $4.99(0.03)^{\mathrm{C}}$ & $33.88(4.65)^{\mathrm{A}}$ & $76.80(12.10)^{\mathrm{A}}$ & $2.30(0.33)^{\mathrm{A}}$ \\
BC & $5.33(0.05)^{\mathrm{B}}$ & $23.23(6.28)^{\mathrm{AB}}$ & $38.00(4.40)^{\mathrm{C}}$ & $1.85(0.33)^{\mathrm{B}}$ \\
SET & $4.93(0.07)^{\mathrm{C}}$ & $12.42(4.26)^{\mathrm{B}}$ & $56.67(11.5)^{\mathrm{B}}$ & $1.25(0.35)^{\mathrm{C}}$ \\
U100 & $5.76(0.01)^{\mathrm{A}}$ & $16.52(7.49)^{\mathrm{B}}$ & $77.40(11.85)^{\mathrm{A}}$ & $2.60(0.44)^{\mathrm{A}}$ \\
YCEM & $4.98(0.15)^{\mathrm{C}}$ & $38.76(7.21)^{\mathrm{A}}$ & $84.17(16.19)^{\mathrm{A}}$ & $2.70(0.63)^{\mathrm{A}}$ \\
\hline
\end{tabular}

Different superscript capital letters in columns show statistical differences for SARCs $(p<0.05)$. ${ }^{*} \mathrm{pH}$ of the eluate after $24 \mathrm{~h}$; ${ }^{* *} \mathrm{DC}$ after photopolymerization for $20 \mathrm{~s}$.

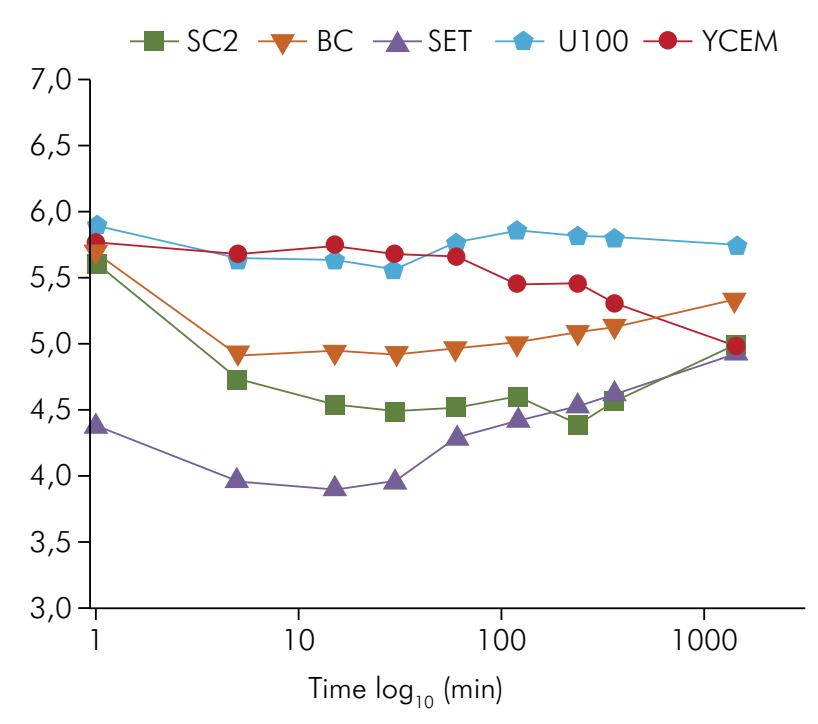

Figure 4. $\mathrm{pH}$ value of the eluate over a 24 -hour storage period

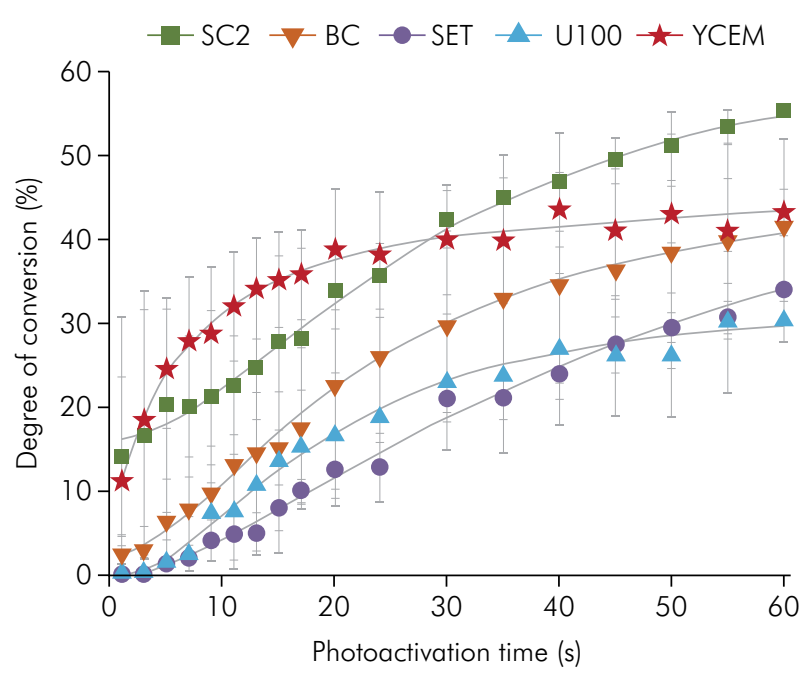

Figure 5. Degree of conversion of SARCs during photoactivation time

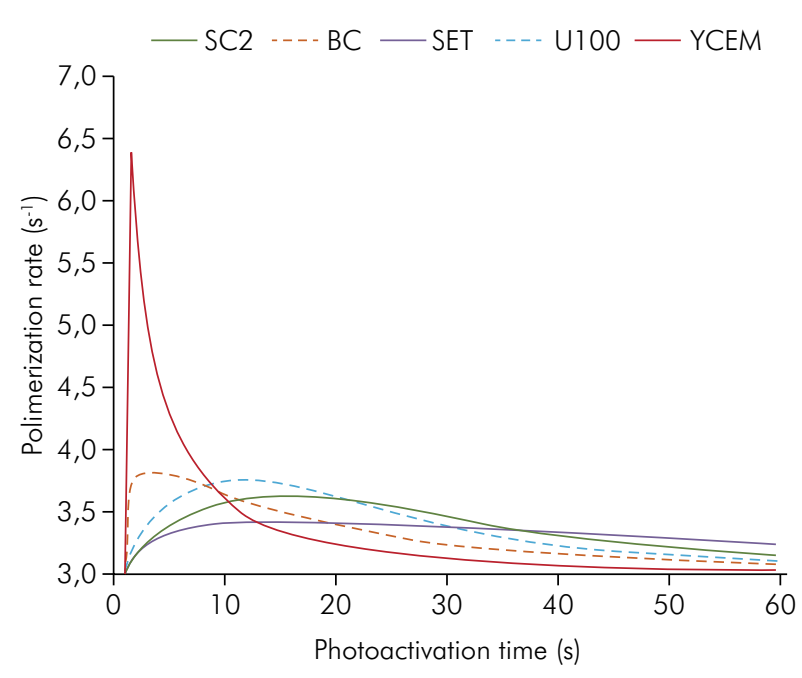

Figure 6. Polymerization rate of SARCs during photoactivation time

be applied with pressure to increase their adaptation to the surface; ${ }^{28.29}$ but the shear bond strength testing design with limited contact area, makes this step difficult and promotes high polymerization stress, causing resin shrinkage away from the dentin surface. Furthermore, the $\mathrm{pH}$ of self-adhesive resin cements is another factor in their performance and must provide the acidity required for demineralizing the substrate, while avoiding excessive hydrophilicity. ${ }^{19}$ The initial drop in $\mathrm{pH}$ observed for the self-adhesive resin cements resulted from activating the acid functional monomers that provide greater wettability and promote dental substrate demineralization, thus allowing their infiltration into the demineralized dentin. After the initial drop in $\mathrm{pH}$, the increase during the time observed in this study was in agreement with the results previously described for the commercial SARCs. ${ }^{19}$ This phenomenon occurs because these functional monomers are subsequently neutralized by alkaline composites and inorganic components of the tooth structure, such as coming into contact with hydroxyapatite, which neutralizes the reaction of acidic monomers from the hydroxyl groups, making the polymer more hydrophobic and less susceptible to degradation. Although there was an incremental increase in $\mathrm{pH}$ during $24 \mathrm{~h}$ storage for all SARCs, except for material YCEM, this phenomenon did not seem be crucial to the longevity of bonding. 
SARC Relyx U100 maintained its SBS results after 6 months, probably because it has MDP acid monomer in its formulation, promoting stable adhesion to dentin by both micromechanical interlocking and chemical bonding through the acid groups. Studies have indicated that the interaction between the tooth surface and the adhesive cements may occur through a satisfactory link between $\mathrm{Ca}^{++}$hydroxyapatite and acid monomers. ${ }^{30,31}$ The acid used in YCEM monomer formulation is unknown. The bonding longevity of this cement was not related to increased $\mathrm{pH}$ over time and appeared to be related to quality of the polymer formed and its interaction with the dentin. Indeed, after 12 months all cements showed significant decrease in bond strength.

The predominance of adhesive failures for SARCs tested in all storage times indicated that there was damage to the bond between the cement and the substrate. This type of surface interaction has been reported for most of the SARCs on the market. ${ }^{10}$ The bond capacity of SARCs can partly or primarily be attributed to their ability to chemically interact with hydroxyapatite. A relatively high proportion of specimens that failed during storage (pre-testing failure) in distilled water or in preparation for the mechanical tests, as seen for materials BC and SC2, may indicate an inability to achieve efficient micromechanical interlocking and chemical bonding, which was reflected in the decrease in bond strength after 6 months of storage.

The degree of demineralization observed by scanning electron microscopy (SEM) showed that the positive control (phosphoric acid etching at $37 \%$ ) was able to fully expose the dentinal tubules and remove the smear layer. When posite control was used, it was unnecessary to perform previous dental structure etching, demineralization and interaction with substrates, because the monomers were formed by acid radicals along with their molecular chains. Thus, the acidity of these monomers did not seem to be sufficient to cause the same degree of dentin demineralization as caused by phosphoric acid. Furthermore, phosphoric acid etching opens the tubules; generates post-operative sensitivity; promotes excessive demineralization; and poor infiltration of monomers. However, the pattern of dentin demineralization for phosphoric acid was not necessary to promote the satisfactory adhesion of SARCs to dentin, as observed in long-term SBS data of U100 and YCEM. In Figure 3, particularly in images $F$ and $G$, it was possible to observe the tubule entrances when materials U100 and YCEM were used.

The acidic $\mathrm{pH}$ of SARCs can interfere with the kinetics of polymerization, and the initial drop in $\mathrm{pH}$ may account for incomplete polymerization of methacrylate acids. The acid monomers are less reactive, yielding lower rates of polymerization and conversion compared with those of conventional resin cements. Previous studies have shown that the addition of acid functional monomers to unmodified (di) methacrylates may compromise the rate and extent of copolymerization. ${ }^{32,33,34}$ This event can be explained by inhibition of the reaction of conversion of the acid groups into free radicals. Terminated radical acid groups are stable, and therefore, less reactive than free radical derivatives of unmodified monomers, thus reducing the speed of polymerization. Furthermore, the degree of conversion (DC) of SARCs occurs by conversion of the monomers into high molecular weight polymers that form the polymeric network. Moreover, the final degree of conversion depends on the chemical characteristics of the monomers in the formulation. A previous study showed that commercial SARCs needed more light exposure time to achieve better degree of conversion results, ${ }^{35}$ which explains the low values obtained with up to $20 \mathrm{~s}$ of light polymerization.

YCEM had the highest rate of polymerization; this may be related to the photoinitiators used in the formulation, which act as reaction catalysts by lowering the activation energy necessary to initiate the polymerization process, and regenerate rapidly to react with another molecule, camphorquinone. Therefore, the immediate mechanical performance of material YCEM was related to the quality of the polymer formed with increased crosslink density, leading to an increased resistance of resin cements. ${ }^{36}$ This mechanism may explain the longevity results of this resin cement. However, a relationship between polymerization and adhesion could not be observed 
for U100. The rates of degree of conversion and kinetics of polymerization profiles suggested the importance of highlighting that light activation time should be longer than forty seconds when cements SC2, BC and SET were used.

The properties of flexural strength (FS) and modulus of elasticity (E) indicated the capacity of the cements to resist high chewing forces and avoid the displacement of indirect restorations. Except for material $\mathrm{BC}$, the other cements reached the minimum FS for dual cementing materials (50 MPa) established by ISO 4049, this could be related to the low bond strength values and the large number of premature failures observed for BC.

Further clinical studies are needed to understand the real performance of these materials for bonding longevity. In addition, manufacturers must review their formulations to provide products with improved properties. The authors rejected the null hypotheses since the values for bond strengths to dentin and other material properties produced by self-adhesive luting agents were not statistically similar.

\section{References}

1. Weiser F, Behr M. Self-adhesive resin cements: a clinical review. J Prosthodont. 2015 Feb;24(2):100-8. https://doi.org/10.1111/jopr.12192

2. Burke FJ, Crisp RJ, Richter B. A practice-based evaluation of the handling of a new self-adhesive universal resin luting material. Int Dent J. 2006 Jun;56(3):142-6. https://doi.org/10.1111/j.1875-595X.2006.tb00086.x

3. Radovic I, Monticelli F, Goracci C, Vulicevic ZR, Ferrari M. Self-adhesive resin cements: a literature review. J Adhes Dent. 2008 Aug;10(4):251-8. https://doi.org/10.3290/i.jad.a13735

4. Skupien JA, Sarkis-Onofre R, Cenci MS, Moraes RR, Pereira-Cenci T. A systematic review of factors associated with the retention of glass fiber posts. Braz Oral Res. 2015;29(1):1-8. https://doi.org/10.1590/1807-3107BOR-2015.vol29.0074

5. Holderegger C, Sailer I, Schuhmacher C, Schläpfer R, Hämmerle C, Fischer J. Shear bond strength of resin cements to human dentin. Dent Mater. 2008 Jul;24(7):944-50. https://doi.org/10.1016/i.dental.2007.11.021

6. Sarkis-Onofre R, Skupien JA, Cenci MS, Moraes RR, Pereira-Cenci T. The role of resin cement on bond strength of glass-fiber posts luted into root canals: a systematic review and meta-analysis of in vitro studies. Oper Dent. 2014 Jan-Feb;39(1):E31-44. https://doi.org/10.2341/13-070-LIT

\section{Conclusion}

All SARCs tested showed a significant reduction in bond strength after 12 months. BisCem and SmartCem2 presented the worst bond strength performance, with no bonding after $24 \mathrm{~h}$ and 6 months respectively. Furthermore, irrespective of the storage period materials U100 and YCEM showed the best long-term dentin bond effectiveness associated with a lower rate of pre-testing failures. The polymerization profile analysis suggested that an increased time of light activation, exceeding that recommended by manufacturers, would be necessary to optimize degree of conversion of SARCs especially for SmartCement2, BisCem and Set PP.

\section{Acknowledgements}

The authors are grateful to Conselho Nacional de Pesquisa (CNPq/Brazil) for the scholarship; to "Financiadora de Estudos e Projetos" (FINEP/Brazil grant 01.10.0709.00) for their support, and to "Centro de Microscopia Eletrônica do Sul" (CEME- SUL) FURG/ Brazil for the SEM analysis.

7. Viotti RG, Kasaz A, Pena CE, Alexandre RS, Arrais CA, Reis AF. Microtensile bond strength of new self-adhesive luting agents and conventional multistep systems. J Prosthet Dent. 2009 Nov;102(5):306-12. https://doi.org/10.1016/S0022-3913(09)60180-3

8. Frassetto A, Navarra CO, Marchesi G, Turco G, Di Lenarda $R$, Breschi $L$ et al. Kinetics of polymerization and contraction stress development in self-adhesive resin cements. Dent Mater. 2012 Sep;28(9):1032-9. https://doi.org/10.1016/i.dental.2012.06.003

9. Yang B, Ludwig K, Adelung R, Kern M. Micro-tensile bond strength of three luting resins to human regional dentin. Dent Mater. 2006 Jan;22(1):45-56. https://doi.org/10.1016/i.dental.2005.02.009

10. De Munck J, Vargas M, Van Landuyt K, Hikita K, Lambrechts P, Van Meerbeek B. Bonding of an auto-adhesive luting material to enamel and dentin. Dent Mater. 2004 Dec;20(10):963-71. https://doi.org/10.1016/i.dental.2004.03.002

11. Ferracane JL, Stansbury JW, Burke FJ. Self-adhesive resin cements - chemistry, properties and clinical considerations. J Oral Rehabil. 2011 Apr;38(4):295-314. https://doi. org/10.1111/i.1365-2842.2010.02148.x PMID:21133983 
12. Abo-Hamar SE, Hiller KA, Jung H, Federlin M, Friedl KH, Schmalz $\mathrm{G}$. Bond strength of a new universal self-adhesive resin luting cement to dentin and enamel. Clin Oral Investig. 2005 Sep;9(3):161-7. https://doi.org/10.1007/s00784-005-0308-5

13. Goracci C, Sadek FT, Fabianelli A, Tay FR, Ferrari M. Evaluation of the adhesion of fiber posts to intraradicular dentin. Oper Dent. 2005 Sep-Oct;30(5):627-35.

14. Aguiar TR, André CB, Correr-Sobrinho L, Arrais CA, Ambrosano GM, Giannini M. Effect of storage times and mechanical load cycling on dentin bond strength of conventional and self-adhesive resin luting cements. J Prosthet Dent. 2014 May;111(5):404-10. https://doi.org/10.1016/i.prosdent.2013.07.016

15. André CB, Aguiar TR, Ayres AP, Ambrosano GM, Giannini $M$. Bond strength of self-adhesive resin cements to dry and moist dentin. Braz Oral Res. 2013 Sep-Oct;27(5):389-95. https://doi.org/10.1590/S1806-83242013000500002

16. Aguiar TR, Di Francescantonio M, Ambrosano GM, Giannini $M$. Effect of curing mode on bond strength of self-adhesive resin luting cements to dentin. J Biomed Mater Res B Appl Biomater. 2010 Apr;93(1):122-7. https://doi.org/10.1002/jbm.b.31566

17. Hitz T, Stawarczyk B, Fischer J, Hämmerle CH, Sailer I. Are self-adhesive resin cements a valid alternative to conventional resin cements? A laboratory study of the longterm bond strength. Dent Mater. 2012 Nov;28(11):1183-90. https://doi.org/10.1016/i.dental.2012.09.006

18. Vaz RR, Hipólito VD, D'Alpino PH, Goes MF. Bond strength and interfacial micromorphology of etch-and-rinse and self-adhesive resin cements to dentin. J Prosthodont. 2012 Feb;21(2):101-11. https://doi.org/10.1111/j.1532-849X.2011.00794.x

19. Zorzin J, Petschelt A, Ebert J, Lohbaver U. pH neutralization and influence on mechanical strength in self-adhesive resin luting agents. Dent Mater. 2012 Jun;28(6):672-9. https://doi.org/10.1016/i.dental.2012.03.005

20. Marghalani HY. Sorption and solubility characteristics of selfadhesive resin cements. Dent Mater. 2012 Oct;28(10):e187-98. https://doi.org/10.1016/j.dental.2012.04.037

21. Aguiar TR, de Oliveira M, Arrais CA, Ambrosano GM, Rueggeberg F, Giannini M. The effect of photopolymerization on the degree of conversion, polymerization kinetic, biaxial flexure strength, and modulus of self-adhesive resin cements. J Prosthet Dent. 2015 Feb;113(2):128-34. https://doi.org/10.1016/j.prosdent.2014.09.011

22. Moraes RR, Boscato N, Jardim PS, Schneider LF. Dual and self-curing potential of self-adhesive resin cements as thin films. Oper Dent. 2011 Nov-Dec;36(6):635-42. https://doi.org/10.2341/10-367-L

23. Ogliari FA, Ely C, Zanchi CH, Fortes CB, Samuel SM, Demarco FF et al. Influence of chain extender length of aromatic dimethacrylates on polymer network development. Dent Mater. 2008 Feb;24(2):165-71. https://doi.org/10.1016/i.dental.2007.03.007

24. Meereis CT, Leal FB, Lima GS, de Carvalho RV, Piva E, Ogliari FA. $\mathrm{BAPO}$ as an alternative photoinitiator for the radical polymerization of dental resins. Dent Mater. 2014 Sep;30(9):945-53. https://doi.org/10.1016/i.dental.2014.05.020
25. Sarr M, Mine A, De Munck J, Cardoso MV, Kane AW, Vreven J et al. Immediate bonding effectiveness of contemporary composite cements to dentin. Clin Oral Investig. 2010 Oct;14(5):569-77. https://doi.org/10.1007/s00784-009-0327-8

26. Han L, Okamoto A, Fukushima M, Okiji T. Evaluation of physical properties and surface degradation of self-adhesive resin cements. Dent Mater J. 2007 Nov;26(6):906-14. https://doi.org/10.4012/dmi.26.906

27. Goracci C, Cury AH, Cantoro A, Papacchini F, Tay FR, Ferrari $M$. Microtensile bond strength and interfacial properties of self-etching and self-adhesive resin cements used to lute composite onlays under different seating forces. J Adhes Dent. 2006 Oct;8(5):327-35.

28. Duarte S Jr, Botta AC, Meire M, Sadan A. Microtensile bond strengths and scanning electron microscopic evaluation of self-adhesive and self-etch resin cements to intact and etched enamel. J Prosthet Dent. 2008 Sep;100(3):203-10. https://doi.org/10.1016/S0022-3913(08)60179-1

29. Chieffi N, Chersoni S, Papacchini F, Vano M, Goracci $C$, Davidson $\mathrm{CL}$ et al. The effect of application sustained seating pressure on adhesive luting procedure. Dent Mater. 2007 Feb;23(2):159-64. https://doi.org/10.1016/i.dental.2006.01.006

30. Monticelli F, Osorio R, Mazzitelli C, Ferrari M, Toledano M. Limited decalcification/diffusion of self-adhesive cements into dentin. J Dent Res. 2008 Oct;87(10):974-9. https://doi.org/10.1177/154405910808701012

31. Manso AP, Silva NR, Bonfante EA, Pegoraro TA, Dias RA, Carvalho RM. Cements and adhesives for all-ceramic restorations [ix.]. Dent Clin North Am. 2011 Apr;55(2):311-32. https://doi.org/10.1016/i.cden.2011.01.011

32. Ferracane JL, Condon JR. Rate of elution of leachable components from composite. Dent Mater. 1990 Oct;6(4):2827. https://doi.org/10.1016/S0109-5641(05)80012-0

33. Sideridou ID, Karabela MM, Vouvoudi EC. Volumetric dimensional changes of dental light-cured dimethacrylate resins after sorption of water or ethanol. Dent Mater. 2008 Aug;24(8):1131-6. https://doi.org/10.1016/j.dental.2007.12.009

34. Ito S, Hashimoto M, Wadgaonkar B, Svizero N, Carvalho RM, Yiu $C$ et al. Effects of resin hydrophilicity on water sorption and changes in modulus of elasticity. Biomaterials. 2005 Nov;26(33):6449-59. https://doi.org/10.1016/i.biomaterials.2005.04.052

35. Tezvergil-Mutluay A, Lassila LV, Vallittu PK. Degree of conversion of dual-cure luting resins light-polymerized through various materials. Acta Odontol Scand. 2007 Aug;65(4):201-5. https://doi.org/10.1080/00016350701311632

36. Ferracane JL. Hygroscopic and hydrolytic effects in dental polymer networks. Dent Mater. 2006 Mar;22(3):211-22. https://doi.org/10.1016/j.dental.2005.05.005 